Research Article

\title{
Heterogeneous Fenton-Like Catalytic Removal of Methylene Blue Dye in Water Using Magnetic Nanocomposite (MCM-41/Magnetite)
}

\author{
André E. Nogueira, Isabela A. Castro, Amanda S. Giroto, and Zuy M. Magriotis \\ Department of Chemistry, Federal University of Lavras, P.O. Box 3037, 37200-000 Lavras, MG, Brazil \\ Correspondence should be addressed to André E. Nogueira; andreesteves86@hotmail.com
}

Received 4 November 2013; Revised 20 February 2014; Accepted 23 February 2014; Published 31 March 2014

Academic Editor: David W. Mazyck

Copyright (C) 2014 André E. Nogueira et al. This is an open access article distributed under the Creative Commons Attribution License, which permits unrestricted use, distribution, and reproduction in any medium, provided the original work is properly cited.

In this work, MCM-41, magnetite (MAG), and a composite of magnetite and MCM-41 (MCM-MAG) were synthesized by a simple route for the production of active systems in the decomposition of organic waste. The materials were characterized by $\mathrm{N}_{2}$ adsorption/desorption, X-ray diffraction analysis (XRD), temperature programmed reduction (TPR), Fourier transform infrared spectroscopy (FTIR), and transmission electron microscopy (TEM). Our results indicated that the decolorization kinetics of the dyes were in the order of MCM-MAG > MCM-41 > magnetite. Mineralization of the dyes was monitored by total organic carbon (TOC) decrease. The dye solutions could be completely decolorized and effectively mineralized, with an average overall TOC removal $43 \%$ for a Fenton-like reaction time of $180 \mathrm{~min}$. The degradation activity of the MCM-MAG was stable during four consecutive experiments, confirming their stability and reusability of the composite. The great advantage of this composite is that it may be easily magnetically recovered and reused.

\section{Introduction}

Currently the efficient use of water is important for industry, as it is crucial for sustainable development and public health. In many cases the generation of contaminated effluents with various types of organic waste, which are rich in microbial or bacterial activity, are involved. This is not appropriate for reuse in agriculture and human consumption [1].

With regard to organic pollutants, we can highlight the textile dyes, which possess a high capacity to modify the environment due to their strong color and visual pollution and also cause changes in biological cycles mainly affecting photosynthesis processes. Besides these facts, studies have shown that some classes of dyes and their byproducts may be carcinogenic and/or mutagenic [2].

In this context, the development of new processes for wastewater treatment in order to immobilize or degrade these compounds in textile industry effluents is very important. An extensively studied alternative is the use of advanced oxidation processes (AOP). These processes are based on the formation of hydroxyl radicals, which are capable of oxidizing contaminants to smaller and less polluting molecules or even mineralize them, turning them into $\mathrm{CO}_{2}, \mathrm{H}_{2} \mathrm{O}$, and inorganic ions from atoms [3].

The development of active heterogeneous systems to promote Fenton chemistry is of considerable interest, since it could offer some advantages over the classical homogeneous Fenton; because there is no sludge formation, the operation is carried out in near neutral $\mathrm{pH}$ and there is the possibility of recycling the iron promoter [4].

The main feature of this technology is the use of iron as a solid catalyst supported on material with high surface area or in the form of poorly soluble magnetic oxides, facilitating the removal of the catalyst for later reuse $[5,6]$. Most works refer to iron catalysts supported on zeolites [7-9] and activated carbon $[10,11]$ for the degradation of organic compounds $[12,13]$.

The purpose of this study was to report the preparation of a composite based on magnetic iron oxide nanoparticles dispersed inside mesoporous silica MCM- 41 and its application 
to the degradation of methylene blue (MB) by heterogeneous Fenton process.

\section{Methodology}

2.1. Synthesis. First, magnetite was prepared by a coprecipitation method, already described in the literature [14]. In a typical procedure, $500 \mathrm{~mL}$ of $0.126 \mathrm{~mol} \mathrm{~L}^{-1} \mathrm{FeSO}_{4} \cdot 7 \mathrm{H}_{2} \mathrm{O}$ solution, $500 \mathrm{~mL}$ of $\mathrm{FeCl}_{3} \cdot 6 \mathrm{H}_{2} \mathrm{O}\left(0.18 \mathrm{~mol} \mathrm{~L}^{-1}\right)$, and $9 \mathrm{~mL}$ of concentrated $\mathrm{HCl}$ solution were quickly added to a basic solution $(53 \mathrm{~mL})$ of $30 \% \mathrm{NH}_{4} \mathrm{OH}$ at $60^{\circ} \mathrm{C}$ under vigorous stirring for 15 minutes. The black precipitate (magnetite) was washed several times until the suspension reached $\mathrm{pH} 8$.

The MCM-composite was obtained using 5\% of magnetite $(\mathrm{m} / \mathrm{m})$. For this, $16 \mathrm{~g}$ of Cetyltrimethylammonium surfactant (CTAB) was dissolved in $300 \mathrm{~mL}$ of sodium hidroxide solution $\left(0.33 \mathrm{~mol} \mathrm{~L}^{-1}\right)$. Next, it was slowly added to $37 \mathrm{~mL}$ of tetraethyl orthosilicate (TEOS), which was left under stirring for 24 hours at room temperature. Afterwards, the magnetite was added to this suspension and left for 4 more hours. Finally, the composite was washed with distilled water, ovendried for 6 hours at $60^{\circ} \mathrm{C}$, and calcined slowly at $600^{\circ} \mathrm{C}$ for $4 \mathrm{~h}$ under a nitrogen flow $\left(100 \mathrm{~mL} \mathrm{~min}^{-1}\right)$. Likewise, the synthesis of MCM-41 was performed in the absence of magnetite.

2.2. Characterization. The materials were characterized by $\mathrm{N}_{2}$ adsorption/desorption measurements at $77 \mathrm{~K}$ in a Quantchrome Autsorb 1 equipment. The surface areas were calculated by the Brunauer-Emmett-Teller (BET) equation and pore size distribution was determined by the Barrett-Joyner-Halenda (BJH) equation [15]. The Fourier transform infrared spectra (FTIR) of adsorbents (in the form of $\mathrm{KBr}$ pellets) were measured using a Digilab Excalibur FTS 3000 series spectrometer in the $400-4000 \mathrm{~cm}^{-1}$ range at a resolution of $4 \mathrm{~cm}^{-1}$. Temperature programmed reduction (TPR) was carried out using an Chembet-3000 (Quantchrome) apparatus under a flow of $20 \mathrm{~mL} \mathrm{~min}^{-1}$ (mixture of $5 \% \mathrm{H}_{2}$ in $\mathrm{N}_{2}$ ), 150 current, and attenuation 16. The X-ray powder patterns were also collected at room temperature in the $2 \theta$ range from $5^{\circ}$ to $70^{\circ}$ with step scan of $0.02^{\circ}$ using a Rigaku D/MAX 2500 diffractometer with a rotary anode ( $\mathrm{Cu} \mathrm{K} \alpha$ radiation) operating at $150 \mathrm{kV}$ and $40 \mathrm{~mA}$. The morphology of the powders was characterized by transmission electron microscopy (TEM) FEI/PHILIPS CM120.

\subsection{Methylene Blue Removal}

2.3.1. Adsorption Kinetics Tests. The adsorption kinetics tests were performed in batch at a temperature of $25 \pm 1^{\circ} \mathrm{C}$. Aqueous solutions of $\mathrm{MB}(10 \mathrm{~mL})$ at a concentration of $50 \mathrm{mg} \cdot \mathrm{L}^{-1}$ were placed under constant stirring in contact with $10 \mathrm{mg}$ of the catalyst, for $0,15,30,60,120$, and 180 minutes. The absorption tests were monitored by UV-visible spectroscopy (Shimadzu UV-1601 PC) at $645 \mathrm{~nm}$, the maximum absorption wavelength of MB. This analysis was used as reference experiment to compare to the degradation profile with respect to the reaction Fenton using $\mathrm{H}_{2} \mathrm{O}_{2}$ to activate the catalysts.
2.3.2. Degradation Tests. The degradation of $\mathrm{MB}$ was performed using $9.9 \mathrm{~mL}$ of $50 \mathrm{mg} \mathrm{L}^{-1}$ of dye suspension, $0.1 \mathrm{~mL}$ of $30 \% \mathrm{H}_{2} \mathrm{O}_{2}$, and $10 \mathrm{mg}$ of catalysts. The suspension was maintained under constant stirring (100 rpm) for $0,15,30$, 60,120 , and 180 minutes. The temperature was set to $25 \pm 1^{\circ} \mathrm{C}$ during the tests.

The reuse of the catalysts was also investigated. In a typical test, $100 \mathrm{mg}$ of the MCM-MAG was placed in contact with $100 \mathrm{~mL}$ of $\mathrm{MB}$ solution $\left(50 \mathrm{mg} \mathrm{L}^{-1}\right)$ and $1 \mathrm{~mL}$ of $\mathrm{H}_{2} \mathrm{O}_{2}$ under shaker at $130 \mathrm{rpm}$ for $180 \mathrm{~min}$. The catalysts were then recovered by filtration, water-washed in order to remove the excess of adsorbed $\mathrm{MB}$, and dried at $60^{\circ} \mathrm{C}$ for $4 \mathrm{~h}$. The materials were subsequently used in another oxidation cycle keeping the same standard conditions and ratio of catalyst/dye.

The degradation was monitored by UV-visible spectroscopy (Shimadzu UV-1601 PC) at $645 \mathrm{~nm}$, the maximum absorption wavelength of $\mathrm{MB}$, and total carbon analysis was performed in the dye suspension on a Shimadzu 500A TOC analyzer, in synthetic air atmosphere.

\section{Results and Discussion}

3.1. Characterizations. In order to investigate the textural properties, $\mathrm{N}_{2}$ adsorption/desorption was evaluated (Figure 1). The adsorption curves show that the amount of $\mathrm{N}_{2}$ adsorbed increases gradually with increasing relative pressure. This can be ascribed to multilayer adsorption. In the range between 0.2 and $0.4 P / P_{0}$ the adsorption strongly increases for MCM-41. It is assumed that this is due to condensation of nitrogen in the mesopores. The MCM-MAG and magnetite samples showed Type I isotherms; thus, the predominance of micropores can be expected [16].

The specific surface area was calculated by the BET equation (Figure 1(a)). The materials showed high surface area values of 1400,247 , and $118 \mathrm{~m}^{2} \mathrm{~g}^{-1}$ for MCM-41, MCMMAG, and magnetite, respectively. The pore size distribution based on BJH calculation method for magnetite, MCM-41, and MCM-MAG was measured (Figure 1(b)). All samples showed a narrow pore distribution wherein MCM-MAG offered the largest pore size (highest peak centered at $18.6 \AA$ ) among the three synthesized samples, and MCM-41 had the smallest pore size (approximately $17.5 \AA$ ).

The infrared spectra are presented in Figure 2. The absorption bands between 1220 and 1070 and $800 \mathrm{~cm}^{-1}$ for MCM-41 and MCM-MAG are assigned to asymmetric and symmetric vibrations of the $\mathrm{Si}-\mathrm{O}$ groups. In the region close to $446 \mathrm{~cm}^{-1}$, the vibration mode of $\mathrm{Si}-\mathrm{O}$ tetrahedral is observed. The samples showed a broad band at $3455 \mathrm{~cm}^{-1}$, which can be ascribed to the silanol and/or hydroxyl group. The latter suggests adsorbed water [17]. Absorption bands of the magnetite spectrum are observed at 572 and $437 \mathrm{~cm}^{-1}$. These are assigned to $\mathrm{Fe}-\mathrm{O}$ stretch vibration modes characteristic of $\mathrm{Fe}_{3} \mathrm{O}_{4}$ [18]. There were no significant changes in the MCM-MAG spectrum, compared to MCM-41. This can be attributed to an overlap of the characteristic bands of magnetite and MCM-41. 


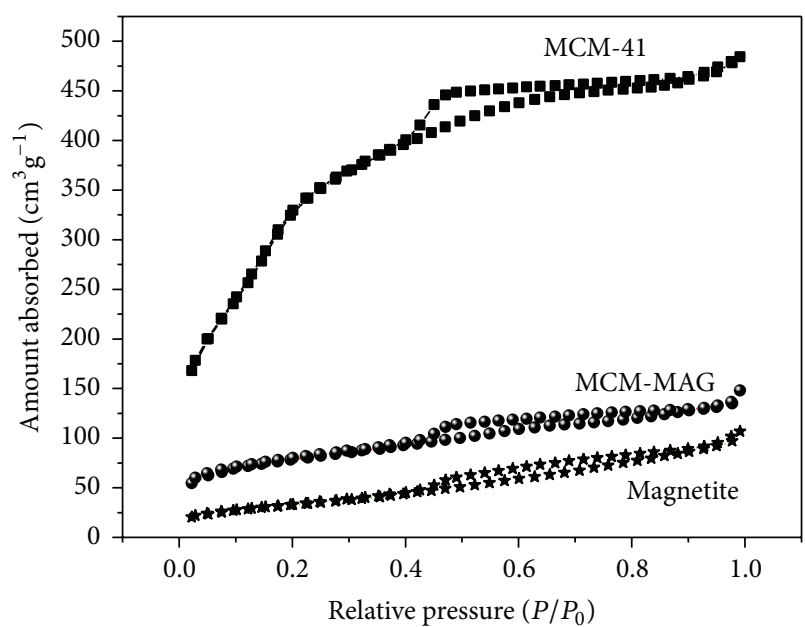

(a)

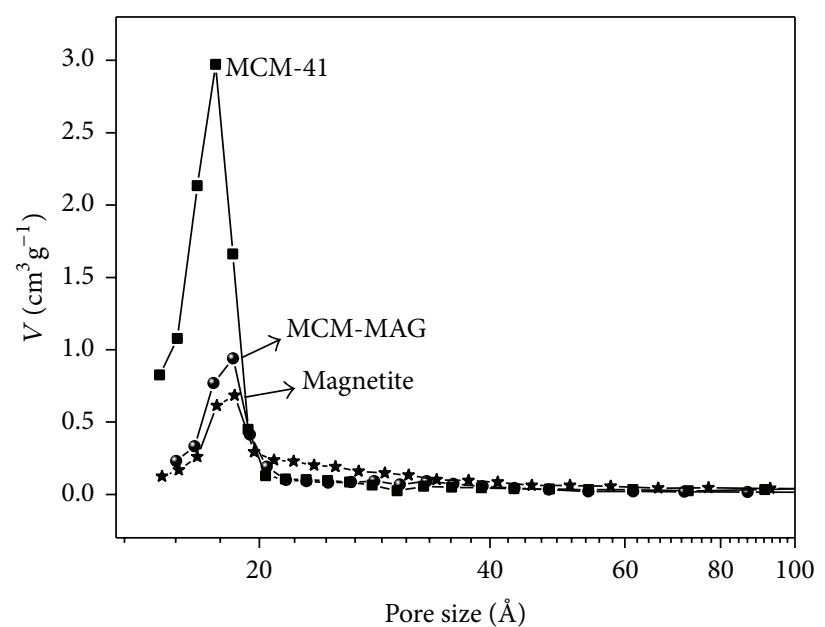

(b)

FIgURE 1: $\mathrm{N}_{2}$ adsorption and desorption isotherms measured at $77 \mathrm{~K}$ (a) and pore size distributions (b).

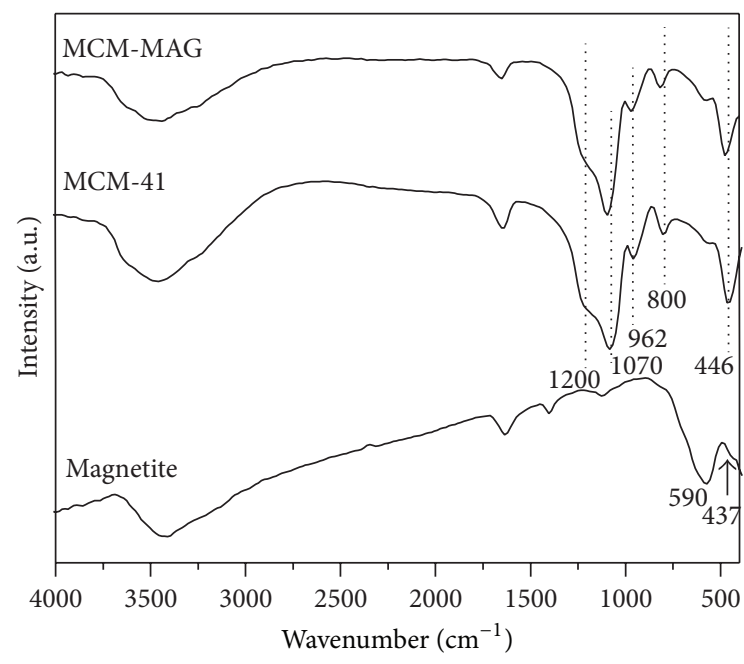

FIGURE 2: FTIR spectrum of the synthesized samples.

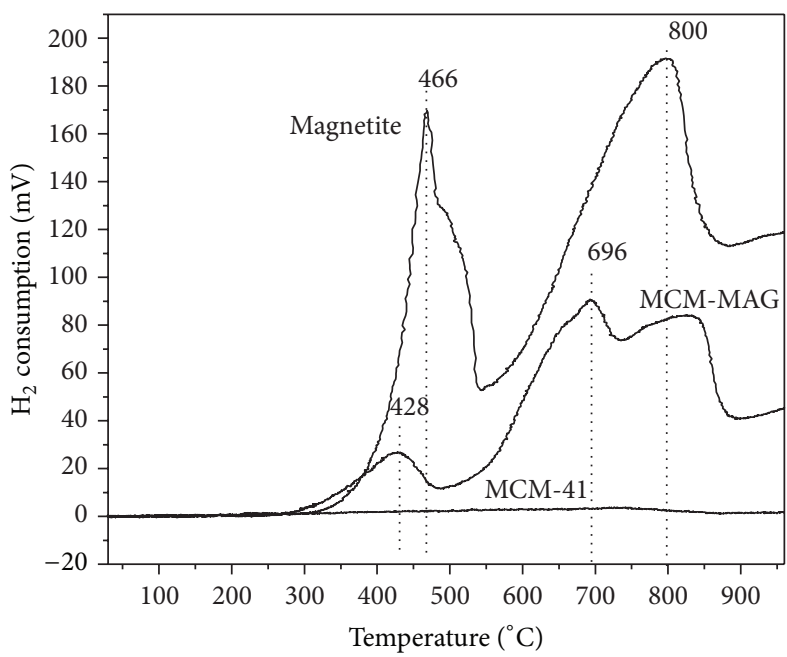

FIGURE 3: Temperature programmed reduction profiles.

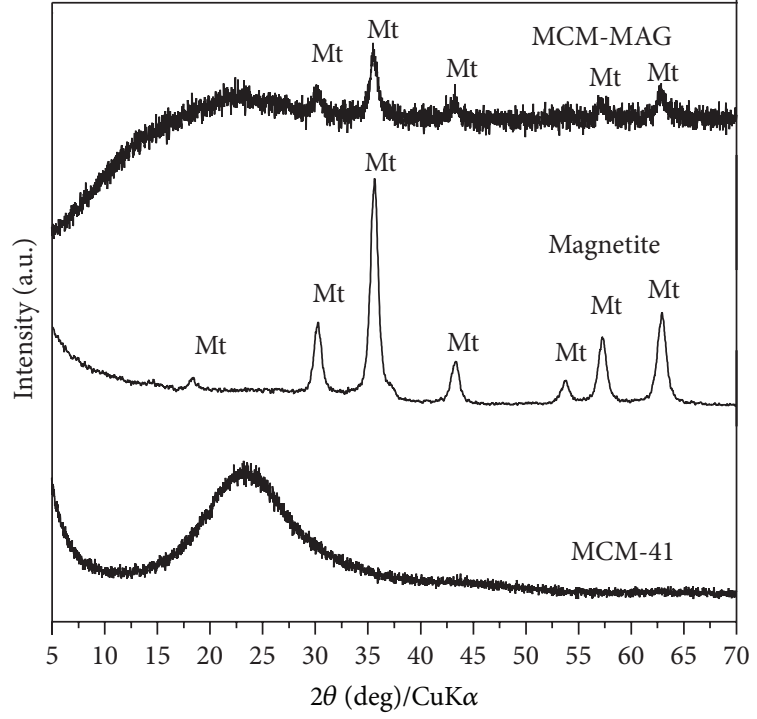

FIGURE 4: The XRD diffraction patterns of MCM-41, MCM-MAG, and magnetite samples.

The synthesized samples were studied by temperatureprogrammed reduction (TPR) using $\mathrm{H}_{2}$ as a reducing gas (Figure 3). In the measurements of MCM-41 no peak reduction was observed. The $\mathrm{H}_{2}$ consumption profile for MAGMCM composite and magnetite showed several peaks related to different iron species. These reduction processes are well known and have been reported in Oliveira et al. (2004) [19]. We have

$$
\underset{\left(\mathrm{Fe}_{3} \mathrm{O}_{4}\right)}{\operatorname{Magnetite}} \longrightarrow \underset{(\mathrm{FeO})}{\text { Wüstite }} \longrightarrow \mathrm{Fe}^{0}
$$

The diffractogram patterns were presented in Figure 4. The XRD pattern of MCM-41 showed no diffraction angle in the analyzed range; this suggests an amorphous phase formation. In contrast, in the XRD patterns of magnetite and 


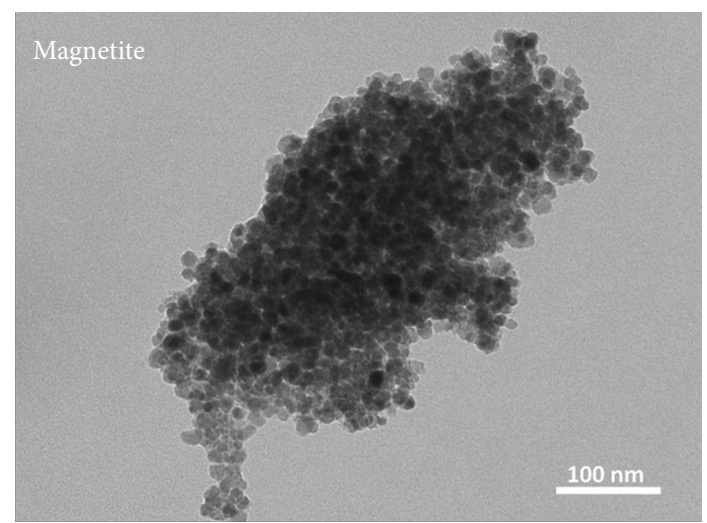

(a)

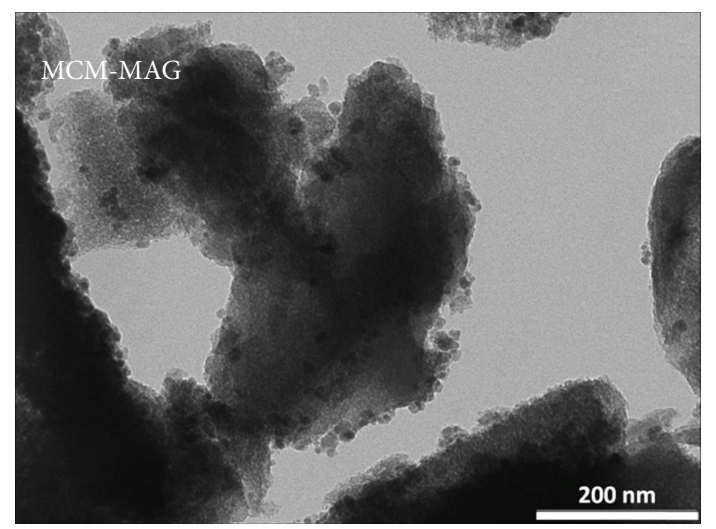

(c)

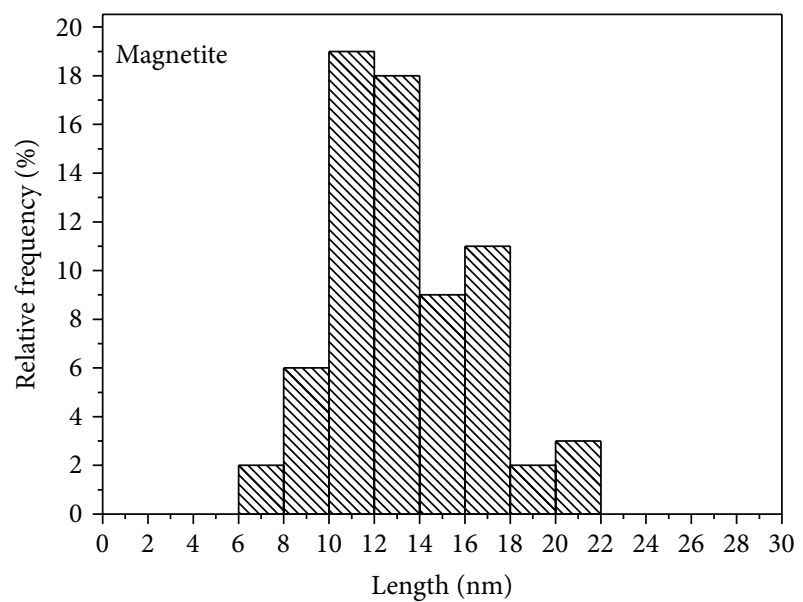

(b)

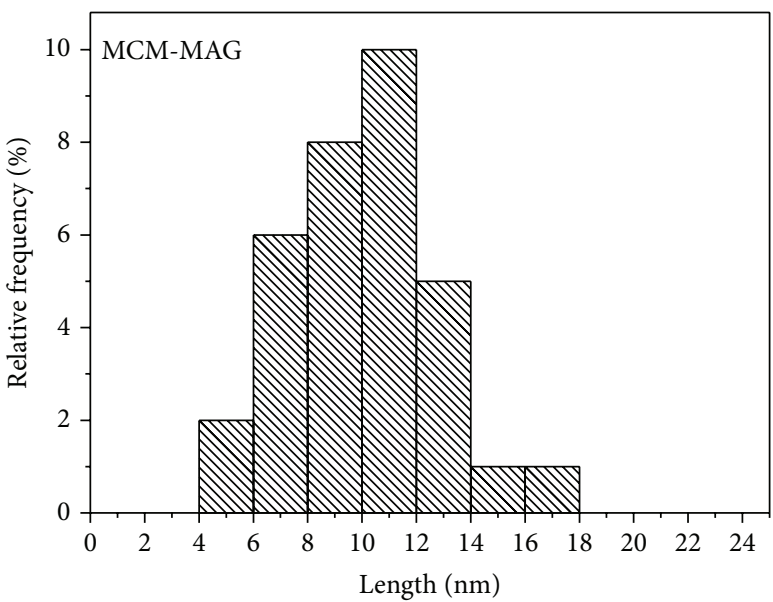

(d)

FIGURE 5: TEM image and histogram analysis for magnetite, (a) and (b), and MCM-MAG, (c) and (d).

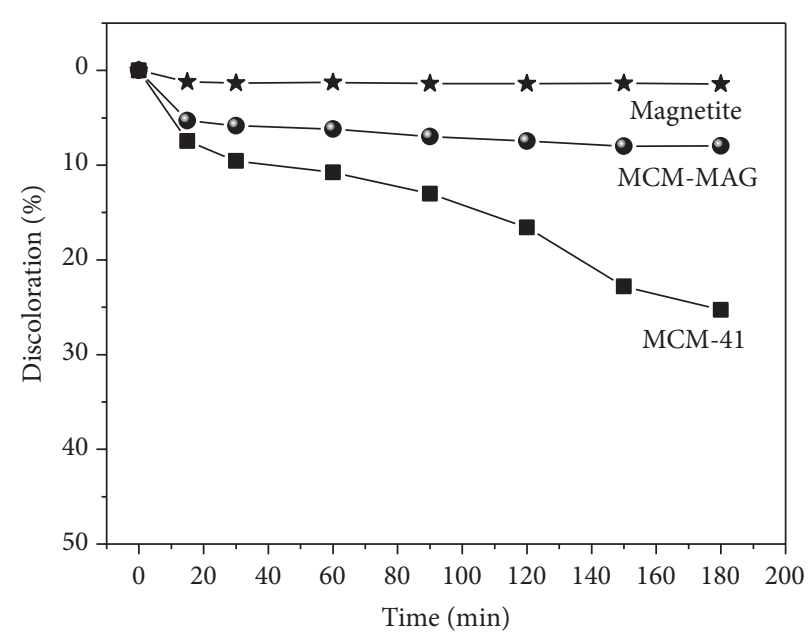

(a)

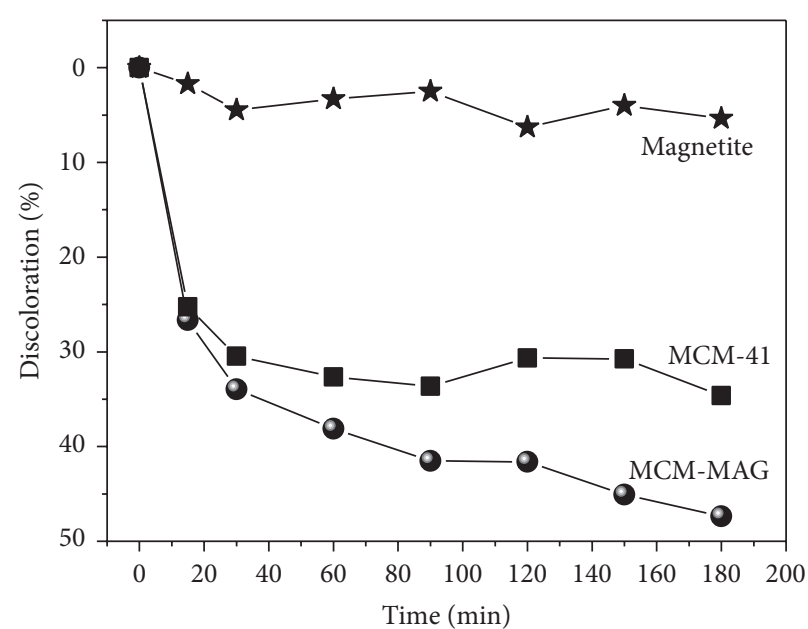

(b)

FIGURE 6: Adsorption kinetics (a) and MB oxidation (b) using the synthesized samples. 


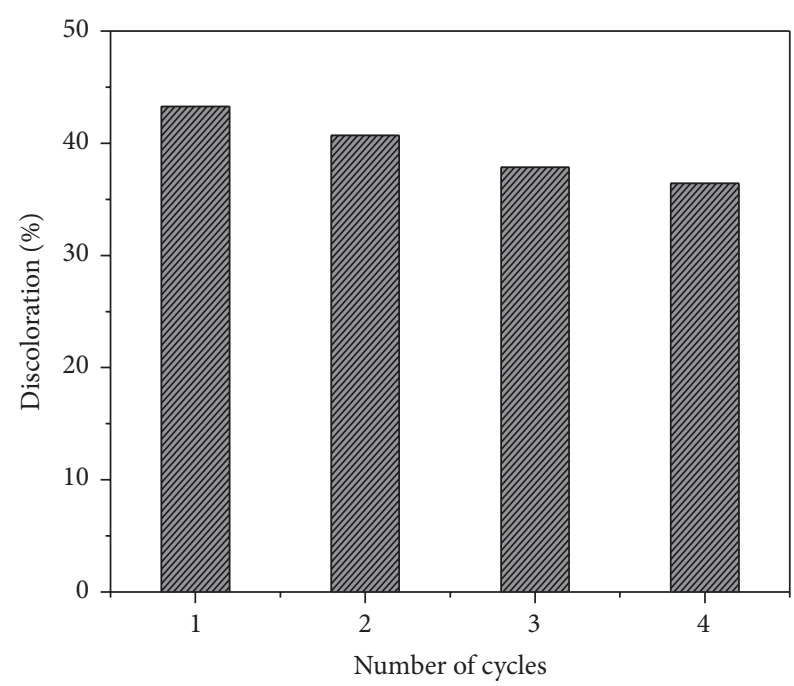

FIGURE 7: Multicycle tests for degradation of MB for $180 \mathrm{~min}$ with MCM-MAG.

the MCM-MAG composite, the crystalline phase formation was observed. Their diffractograms showed characteristic peaks of the iron magnetite phases (JCPDS: 19-0629) at $2 \theta$ $=18.3^{\circ}, 30.2^{\circ}, 35.6^{\circ}, 43.3^{\circ}, 53.7^{\circ}, 57.2^{\circ}$, and $62.9^{\circ}$ [20].

The crystallite size plays an important role and has a high influence on the surface area of synthesized samples and the surface reactions. Thus, we evaluated the average size of the magnetite crystals produced. To this end, we used the information and the domain of the XRD crystallographic coherence. It was calculated employing Scherrer's equation. The particle size was about $12 \mathrm{~nm}$ [21].

Typical TEM micrographs for magnetite and MCMMAG are shown in Figure 5. It is clear that pure $\mathrm{Fe}_{3} \mathrm{O}_{4}$ nanoparticles were quite agglomerated, with a mean diameter of $13 \mathrm{~nm}$, while TEM image of MCM-MAG showed less agglomerated magnetite nanoparticles in the surface of MCM-41 with a mean diameter of $11 \mathrm{~nm}$.

3.2. Methylene Blue Removal. To verify the adsorption and the oxidation effect of the synthesized samples, MB was used as an organic dye model molecule. This compound was chosen due to its ease of monitoring by simple techniques such as UV-visible spectroscopy at its maximum absorption wavelength, $645 \mathrm{~nm}$. The adsorption kinetics process was controlled by measuring the discoloration of the dye solution in a batch adsorption experiment, with the magnetite, MCM-MAG, and MCM-41 (Figure 6(a)). We observed that the adsorption capacity was low for the samples, with a maximum at 25\%, approximately, for MCM-41. Figure 6(b) shows the $\mathrm{MB}$ dye degradation profile in $\mathrm{H}_{2} \mathrm{O}_{2}$ presence by heterogeneous reaction.

The kinetic study of Fenton process can be performed by assuming that the reaction between hydroxyl radicals and the pollutant is the rate determining step. Thus, by assuming that $\mathrm{OH}$ instantaneous concentration was a constant,
MB degradation could be described by a pseudo-first-order kinetic expression:

$$
-\frac{\mathrm{d} C}{\mathrm{~d} t}=k \times C_{\text {oH }} \times C=k_{\text {app }} \times C \longrightarrow-\ln \frac{C}{C_{0}}=k_{\text {app } \times} t,
$$

where $C$ is the $\mathrm{MB}$ concentration, $\mathrm{mg} \cdot \mathrm{L}^{-1}, k$ is the reaction rate constant, and $k_{\text {app }}$ is the apparent pseudo-first-order constant. Straight lines passing through the origin fit the degradation data well (the coefficient of linear regression, $r$, is $0.81,0.92$, and 0.86 for magnetite, MCM-MAG, and MCM41 , resp.) and from the slopes, $k_{\text {app }}$ values were $0.0002,0.0018$, and $0.0013 \mathrm{~min}^{-1}$ for the systems catalyzed by magnetite, MCM-MAG, and MCM-41.

The $k_{\text {app }}$ of the systems with MCM-MAG were higher than that of the system with only magnetite or MCM-41, indicating that composite could improve the degradation efficiency of heterogeneous Fenton reaction. A higher removal was observed for the MCM-MAG composite after $90 \mathrm{~min}$ of reaction, suggesting that the combination of magnetite oxide with mesoporous MCM-41 may offer synergistic reaction routes for the catalytic oxidation of target compounds. However, the color removal from the MB solution does not indicate that there was complete oxidation of the dye. To understand the color removal from the dye solution, the degradation reaction was monitored by total organic carbon analysis (TOC) in order to obtain information about the possible mineralization of the organic compound, by removing carbon from the dye solution.

From these results we can conclude that the composite was more active in carbon removal from the dye solution after $180 \mathrm{~min}$ of reaction, removing $43 \%$ of the carbon solution, followed by MCM- 41 with $18 \%$ and $3 \%$ for magnetite, which is consistent with the analysis obtained by UV-VIS, as expected, evidencing the mineralization of the organic compound.

The reuse test was performed in order to evaluate the catalytic activity of MCM-MAG during successive experiments and thus to observe the possibility of catalyst reuse. Figure 7 shows the discoloration efficiency of MB in four consecutive runs. The result showed that the activity of the MB decreased gradually during four successive runs. However, the result showed that the MCM-MAG maintained high activity for the degradation of $\mathrm{MB}$ during four cycle experiments. This indicates that the MCM-MAG is mechanically stable and reusable under these experimental conditions.

\section{Conclusions}

In this work MCM-MAG was successfully synthesized, with magnetite particles well dispersed on the surface of MCM- 41 . The composite showed very good catalytic performance for $\mathrm{MB}$ organic dye oxidation in $\mathrm{H}_{2} \mathrm{O}_{2}$ presence, after 90 min of reaction, compared with magnetite and MCM-41, suggesting that the combination of magnetite oxide with mesoporous MCM-41 may offer synergistic reaction routes for the catalytic oxidation of target compounds. These studies revealed that the dye removal occurs through a Fenton process system by the composite, whereas for the MCM-41 the dye removal 
occurs mainly via adsorption. In addition to the high catalytic activity for the MCM-MAG composite in the heterogeneous Fenton reaction, it should also be reported that this process provides an easy recovery of the catalyst due to presence of magnetic properties in the composite. It was also observed that catalytic behavior could be reproduced in consecutive experiments without a considerable drop in the process efficiency.

\section{Conflict of Interests}

The authors declare that there is no conflict of interests regarding the publication of this paper.

\section{References}

[1] H. A. J. L. Mourão, A. R. Malagutti, and C. Ribeiro, "Synthesis of $\mathrm{TiO}_{2}$-coated $\mathrm{CoFe}_{2} \mathrm{O}_{4}$ photocatalysts applied to the photodegradation of atrazine and rhodamine B in water," Applied Catalysis A: General, vol. 382, no. 2, pp. 284-292, 2010.

[2] A. Kunz, P. Peralta-Zamora, S. G. Moraes, and N. Durán, "Novas tendências no tratamento de efluentes têxteis," Química Nova, vol. 25, pp. 78-82, 2002.

[3] I. Oller, S. Malato, and J. A. Sánchez-Pérez, "Combination of advanced oxidation processes and biological treatments for wastewater decontamination-a review," Science of the Total Environment, vol. 409, no. 20, pp. 4141-4166, 2011.

[4] R. C. C. Costa, F. C. C. Moura, P. E. F. Oliveira, F. Magalhães, J. D. Ardisson, and R. M. Lago, "Controlled reduction of red mud waste to produce active systems for environmental applications: Heterogeneous Fenton reaction and reduction of Cr(VI)," Chemosphere, vol. 78, no. 9, pp. 1116-1120, 2010.

[5] S.-S. Lin and M. D. Gurol, "Catalytic decomposition of hydrogen peroxide on iron oxide: kinetics, mechanism, and implications," Environmental Science and Technology, vol. 32, no. 10, pp. 1417-1423, 1998.

[6] M.-C. Lu, J.-N. Chen, and H.-H. Huang, "Role of goethite dissolution in the oxidation of 2-chlorophenol with hydrogen peroxide," Chemosphere, vol. 46, no. 1, pp. 131-136, 2002.

[7] S. Chou, C.-C. Liao, S.-H. Perng, and S.-H. Chang, "Factors influencing the preparation of supported iron oxide in fluidized-bed crystallization," Chemosphere, vol. 54, no. 7, pp. 859-866, 2004.

[8] O. A. Makhotkina, E. V. Kuznetsova, and S. V. Preis, "Catalytic detoxification of 1,1-dimethylhydrazine aqueous solutions in heterogeneous Fenton system," Applied Catalysis B: Environmental, vol. 68, no. 3-4, pp. 85-91, 2006.

[9] J. H. Ramirez, C. A. Costa, and L. M. Madeira, "Experimental design to optimize the degradation of the synthetic dye Orange II using Fenton's reagent," Catalysis Today, vol. 107-108, pp. 6876, 2005.

[10] T. L. P. Dantas, V. P. Mendonça, H. J. José, A. E. Rodrigues, and R. F. P. M. Moreira, "Treatment of textile wastewater by heterogeneous Fenton process using a new composite $\mathrm{Fe}_{2} \mathrm{O}_{3}$ /carbon," Chemical Engineering Journal, vol. 118, no. 1-2, pp. 77-82, 2006.

[11] F. C. C. Moura, M. H. Araujo, R. C. C. Costa et al., "Efficient use of $\mathrm{Fe}$ metal as an electron transfer agent in a heterogeneous Fenton system based on $\mathrm{Fe} 0 / \mathrm{Fe} 3 \mathrm{O} 4$ composites," Chemosphere, vol. 60, no. 8, pp. 1118-1123, 2005.

[12] S.-H. Kong, R. J. Watts, and J.-H. Choi, "Treatment of petroleum-contaminated soils using iron mineral catalyzed hydrogen peroxide," Chemosphere, vol. 37, no. 8, pp. 1473-1482, 1998.

[13] R. Dalla Villa and R. F. Pupo Nogueira, "Oxidation of p,p' DDT and p, $\mathrm{p}^{\prime}$-DDE in highly and long-term contaminated soil using Fenton reaction in a slurry system," Science of the Total Environment, vol. 371, no. 1-3, pp. 11-18, 2006.

[14] N. M. Gribanov, E. E. Bibik, O. V. Buzunov, and V. N. Naumov, "Physico-chemical regularities of obtaining highly dispersed magnetite by the method of chemical condensation," Journal of Magnetism and Magnetic Materials, vol. 85, no. 1-3, pp. 7-10, 1990.

[15] S. J. Gregg, "Adsorption of gases-tool for the study of the texture of solids," Studies in Surface Science and Catalysis, vol. 10, pp. 153-164, 1982.

[16] S. Sadasivan and G. B. Sukhorukov, "Fabrication of hollow multifunctional spheres containing MCM-41 nanoparticles and magnetite nanoparticles using layer-by-layer method," Journal of Colloid and Interface Science, vol. 304, no. 2, pp. 437-441, 2006.

[17] K. Vidya, N. M. Gupta, and P. Selvam, "Influence of ph on the sorption behaviour of uranyl ions in mesoporous MCM- 41 and MCM-48 molecular sieves," Materials Research Bulletin, vol. 39, no. 13, pp. 2035-2048, 2004.

[18] X.-M. Liu and J.-K. Kim, "Solvothermal synthesis and magnetic properties of magnetite nanoplatelets," Materials Letters, vol. 63, no. 3-4, pp. 428-430, 2009.

[19] L. C. A. Oliveira, J. D. Fabris, R. R. V. A. Rios, W. N. Mussel, and R. M. Lago, " $\mathrm{Fe}_{3-\mathrm{x}} \mathrm{Mn}_{\mathrm{x}} \mathrm{O}_{4}$ catalysts: phase transformations and carbon monoxide oxidation," Applied Catalysis A: General, vol. 259, no. 2, pp. 253-259, 2004.

[20] X. Liang, S. Zhu, Y. Zhong et al., "The remarkable effect of vanadium doping on the adsorption and catalytic activity of magnetite in the decolorization of methylene blue," Applied Catalysis B: Environmental, vol. 97, no. 1-2, pp. 151-159, 2010.

[21] J. R. C. Salgado and E. R. Gonzalez, "Correlação entre a atividade catalítica e o tamanho de partículas de $\mathrm{Pt} / \mathrm{C}$ preparados por diferentes métodos," Eclética Química, vol. 28, pp. 77-85, 2003. 

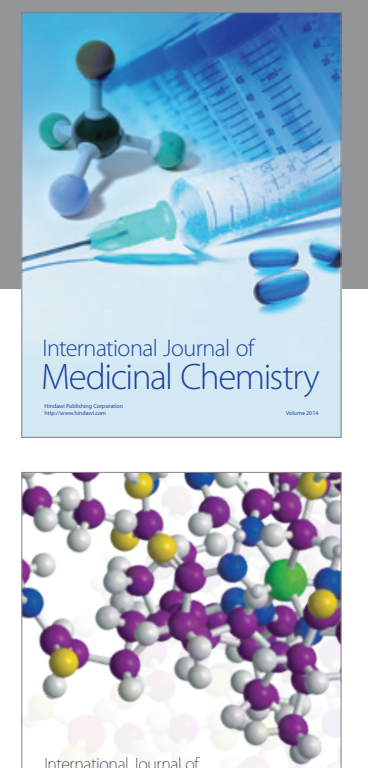

\section{Carbohydrate} Chemistry

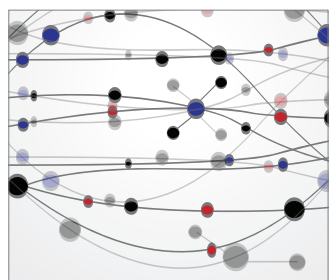

The Scientific World Journal
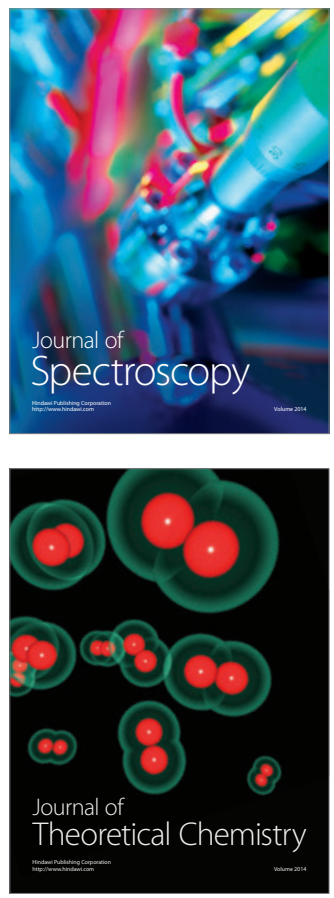
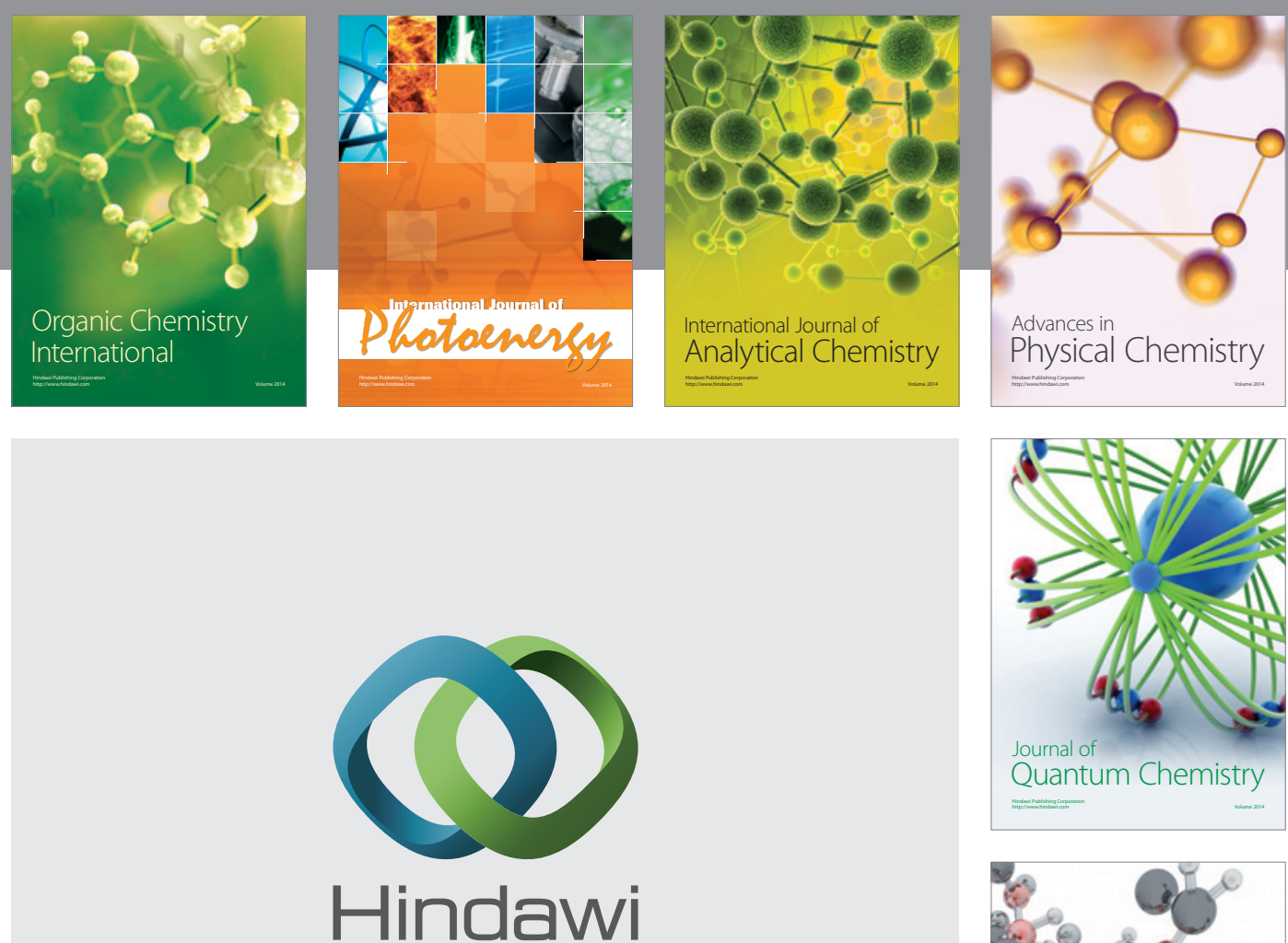

Submit your manuscripts at

http://www.hindawi.com

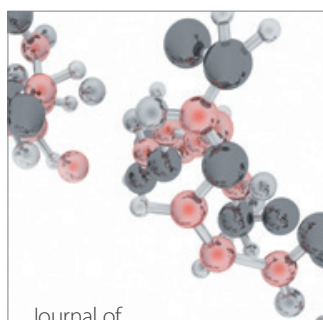

Analytical Methods

in Chemistry

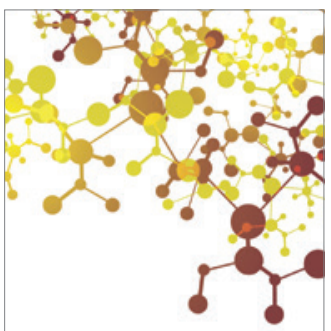

Journal of

Applied Chemistry

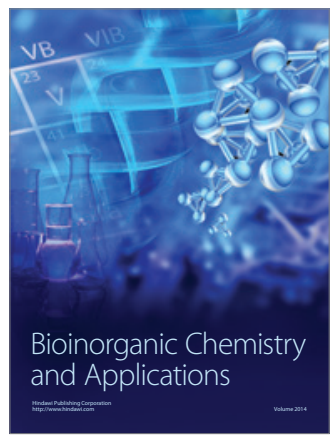

Inorganic Chemistry
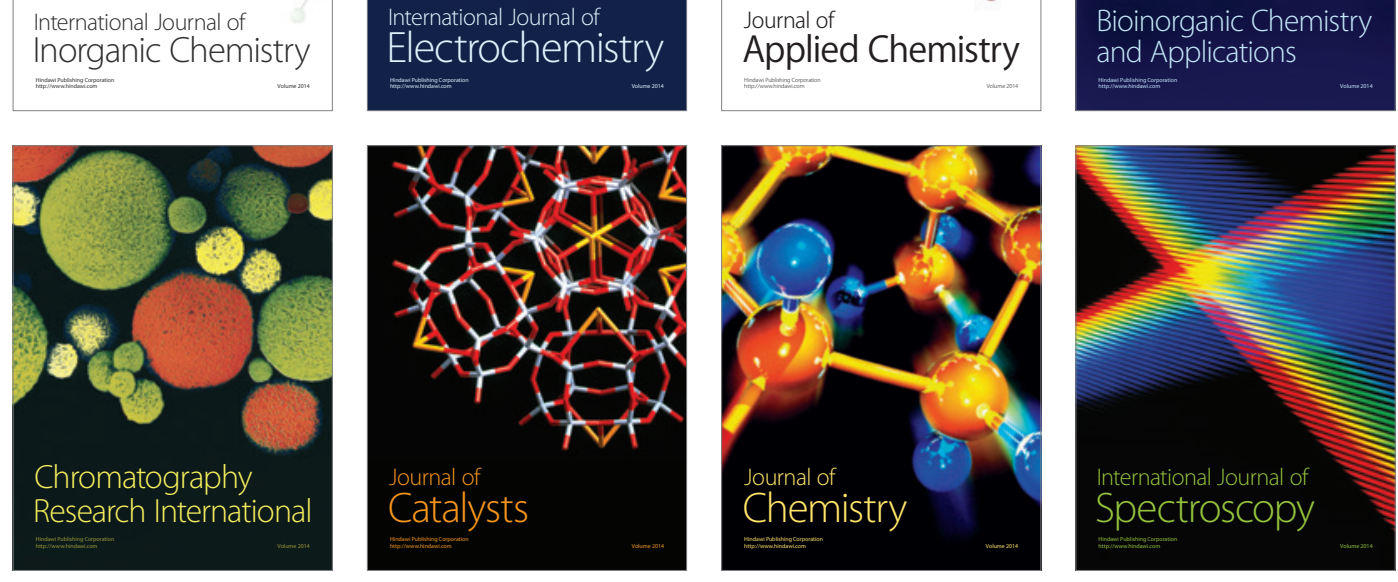